\title{
Acknowledgment to Reviewers of Plasma in 2021
}

\author{
Plasma Editorial Office
}

Citation: Plasma Editorial Office. Acknowledgment to Reviewers of Plasma in 2021. Plasma 2022, 5, 74. https://doi.org/10.3390/

plasma5010006

Published: 29 January 2022

Publisher's Note: MDPI stays neutral with regard to jurisdictional claims in published maps and institutional affiliations.

Copyright: () 2022 by the author. Licensee MDPI, Basel, Switzerland. This article is an open access article distributed under the terms and conditions of the Creative Commons Attribution (CC BY) license (https://creativecommons.org/licenses/by/4.0/).

MDPI AG, St. Alban-Anlage 66, 4052 Basel, Switzerland

Rigorous peer-reviews are the basis of high-quality academic publishing. Thanks to the great efforts of our reviewers, Plasma was able to maintain its standards for the high quality of its published papers. Thanks to the contribution of our reviewers, in 2021, the median time to first decision was 23 days and the median time to publication was 51 days. The editors would like to extend their gratitude and recognition to the following reviewers for their precious time and dedication, regardless of whether the papers they reviewed were finally published:

Ahmad Hamdan

Alessandro Fassina

Alexander Kukushkin

Alexey Vizir

Andrea Zille

Andreas Hoffmann

Andreas Kiontke

Andree Piwowarczyk

Andrey A. Samokhvalov

Antony Ananth

Arkadiusz Dobrzycki

Arnesh K. Bose

Barbara Zaniol

Bogdan Mihalcea

Brunello Tirozzi

Ciprian Dumitrache

Couedel Lenaic

Daniele Desideri

Daniil L. Marinov

Davide Rocco

Diego Marcuzzi

Dušan Kováčik

Efim Oks

Fabio Sattin

Frank R. Graziani

František Krčma

Fruit Gabriel

Gennady Miloshevsky
Hafiz Muhammad Salman Ajmal Heung-Sik Tae

Igor N. Sereda

Ilya Valuev

Iuliana Motrescu

Jon Tomas Gudmundsson

Jose A. Pérez-Hernández

Juan Manuel Díaz-Cabrera

Kamel Ourabah

Karla Mossi

Lazar Friedland

Lennart Stenflo

Luigi G. Celona

Marco Sumini

Martin Cada

Matthias Schnuerer

Maxime Lesur

Min-Chang Lee

Mohammed Koubiti

Nishida Robert

Rodrigo Sávio Pessoa

Sergey Khrapak

Valery Lisitsa

Vassiliki Kontargyri

Yusuke Sakai

Žiga Gosar

Zoran Simić 